\title{
The Effect of Material Static Mechanical Properties on the Fatigue Crack Initiation Life of Rail Fastening Clips
}

\author{
Y. Liu $\left(\mathbb{D},{ }^{1,2}\right.$ Qiutong Li $\left(\mathbb{D},{ }^{1,2}\right.$ Xiujie Jiang $\mathbb{D}^{1},{ }^{1}$ Huan Liu $\left(\mathbb{D},{ }^{3}\right.$ Xianpu Yuan $\mathbb{D},{ }^{1,2}$ \\ and Zhehao Zhu $\mathbb{1 D}^{4}$ \\ ${ }^{1}$ Shanghai Research Institute of Materials, 99 Handan Road, Shanghai 200437, China \\ ${ }^{2}$ Shanghai Engineering Research Center of Earthquake Energy Dissipation, 99 Road Handan, Shanghai 200437, China \\ ${ }^{3}$ Shanghai Polytechnic University, 2360 Jin Hai Road, Shanghai 201209, China \\ ${ }^{4}$ Ecole des Ponts ParisTech, Laboratoire Navier, 6-8 Av. Blaise Pascal, Marne La Vallée, Cedex 2 77455, France \\ Correspondence should be addressed to Y. Liu; 15000600002@163.com, Qiutong Li; lqt910818@163.com, and Xiujie Jiang; \\ 18862143063@163.com
}

Received 26 July 2021; Revised 9 September 2021; Accepted 11 September 2021; Published 30 September 2021

Academic Editor: Yi Zhang

Copyright (C) 2021 Y. Liu et al. This is an open access article distributed under the Creative Commons Attribution License, which permits unrestricted use, distribution, and reproduction in any medium, provided the original work is properly cited.

\begin{abstract}
This paper aimed to study the effect of material static mechanical properties on the fatigue crack initiation life of $\omega$-shaped rail fastening clips, in which the Vossloh 300-1 fastener system was taken as an example. The static mechanical properties of 38Si7 steel (the material of the clip) were first investigated through a series of uniaxial tensile tests. According to the experimental outcomes, a classic assembly system was simulated afterwards using the finite element analysis (FEA) method. On the basis of the Brown-Miller criterion, an in-depth numerical study regarding the critical plane was realized, which allowed fatigue crack initiation to be successfully reproduced by FEA. Finally, a detailed parametric study was performed with the relevant sensitivity analysis. The results showed that the initiation and progression of fatigue cracks in the fastening clip occur in the plane of the maximum shear strain. The fatigue crack initiation life of the fastening clip was extremely sensitive to the elastic modulus, especially more sensitive to the tensile strength. From an engineering viewpoint, the fatigue resistance of the fastening clip could be boosted by (i) increasing the tensile strength of the material to at least $1450 \mathrm{MPa}$ and (ii) rendering the elastic modulus smaller than $160 \mathrm{GPa}$.
\end{abstract}

\section{Introduction}

With the development of the modern economy, high-speed railways have become an increasingly important part of the current society. Under long-term traffic alternative loading, several catastrophic sequences (such as corrosion, cracks, and fractures) might be attributed to the failure of rail fastening clips. For instance, $\omega$-clip fractures appear frequently in some high-speed railway lines [1-3], leading to malfunctions of the total railway and running comfort. This engineering drawback explains the particular attention given to experimental/theoretical studies focusing on this aspect.

Considerable research has been devoted to examining this engaging engineering topic over the past 20 years. Unfortunately, diverse viewpoints are frequently presented in the published literature, and no clear consensus has been attained. Many researchers [1-7] argued that the failure of the rail clip was largely due to the resonance induced by rail corrugation; conversely, other researchers [8-10] stated that the rail clip was prone to failure under heavy axis loads. To the authors' knowledge, fatigue failure of a rail clip may occur due to the combination of multiaxial loads and complex geometric structures. In addition, many scholars $[1,3,6,7,11,12]$ performed fatigue experiments and numerical simulations of rail fastening clips and found that the failure crack was initiated at the position of the maximum von Mises stress. In terms of studying the factors that influence the fatigue lives of rail fastening clips, Zhu et al. [2] established a 5-part structure model including a short rail, a bolt gasket, a clip, an insulating spacer, and a gauge apron to study the mechanical behaviour of the rail clip induced by vehicle dynamic loads. Qi et al. [4] established a 5-part 
structure model of the $\omega$-shaped clip as well and found that the fatigue resistance of the fastening clip could be improved by increasing the fastener stiffness. Gao et al. [5, 6] introduced a one-part clip model with simplified boundary conditions according to the assembly test in the laboratory in order to analyse the failure mechanism of the W1-type fastening clip in high-speed railways. Mohammadzadeh et al. $[13,14]$ modelled only one half of the SKL14 clip to assess the fracture reliability of crack growth in the spring clip. Xin et al. [11], Xiao et al. [15], Yang [16], and Hasap et al. [17] found that the fatigue life of e-shaped fastening clips decreased dramatically with the increase in clip displacement during installation. Wu et al. [18], Liu [19], and Liu [20] found that the fatigue life of W1 fastening clips was negatively correlated with the amplitude of the alternating load. Wang [21] reported that the maximum stress of the fastening clip gradually increased with the increase in the friction coefficient between the fastening clip and gauge apron, thus facilitating crack initiation.

The literature review in the previous section demonstrates that the variation pattern of the fastening clip fatigue life with the installation process, cycle load condition, and system stiffness is already well understood. In addition to external factors, material static mechanical properties, surface conditions, size effects, etc., are all capable of considerably affecting the fatigue life of fastening clips. However, the influences of all these parameters have seldom been studied, and many uncertainties remain in this area, thus hindering the development of the mechanism behind. Manouchehrynia and Abdullah [22] conducted a reliability assessment to predict the fatigue of an automobile coil spring during campus, urban, and highway road surfaces and found that the Morrow model could predict a safe region of a lift data point for the three road surfaces. Abdullah et al. [23] used strain-life approaches of Coffin-Manson and Morrow and Smith-Watson-Topper (SWT) models to predict the fatigue life of the leaf spring under highway, uphill, and downhill data and found that the leaf spring had the highest fatigue life of 1,544 cycles/block under highway data. Zhang et al. [24] found that the fatigue resistance of a nickel-based superalloy was related to the heat treatment procedures applied. Wang et al. [25] investigated the effect of the modulus of the asphalt mixture at the bottom layer on the mechanical response of the bridge pavement and found that the application of a high-modulus asphalt mixture as the bottom asphalt layer decreased the stress level of the pavement structure. Zhao and Ding [26] analysed the microstructure and mechanical properties of as-deposited, quenched and tempered (QT), and stressrelief annealed (SR) specimens of 24CrNiMo alloy steel; they found that the QT specimens had the smallest wear and thermal fatigue crack lengths, excellent resistance to friction and wear performance, and prevention of crack growth, with ideal comprehensive properties. Therefore, studying the effect of material static mechanical properties on rail fastening clips is of great significance since these findings are helpful for suppliers to provide theoretical guidance to implement proper heat treatments in the manufacturing process.
To fill these gaps in knowledge, based on previous research [27-30], this paper takes the $\omega$-shaped fastening clip of the Vossloh 300-1 fastener system, which is commonly used for high-speed railways, as the research subject. A series of uniaxial tensile tests were first performed on the fastening clip material 38Si7 at three different stages. Then, based on the measured performance data of the fastening clip material, a finite element (FE) model of the complete fastener system was constructed. The critical plane method was subsequently employed to identify the critical plane at the critical point, and the fatigue crack initiation life of the fastening clip was predicted following the Brown-Miller criterion. Finally, the effects of the material static mechanical properties on the fatigue crack initiation life of the fastening clip were analysed, and a sensitivity analysis of the material static properties was performed. The findings of this study would be very helpful in (i) finding ways to effectively improve the fatigue resistance of fastening clips from the perspective of material performance and (ii) providing a theoretical framework for the advanced selection of fastening clip materials for use in engineering applications.

\section{Materials and Methods}

Among the studies of multiaxial fatigue, critical plane approaches are the mainstream [31-50]. Zhu et al. [49] evaluated and compared four typical critical plane criteria (Fatemi-Socie, Wang-Brown, modified Smith-Watson-Topper, and proposed modified generalized strain energy) for multiaxial fatigue analysis of ductile and brittle materials under four multiaxial loading conditions and found that criteria with additional material constants yielded robust life predictions for different materials. Liao et al. [50] combined the critical plane and critical distance approaches to analyse multiaxial fatigue lifetime predictions for notched components and found that using this combined approach provided better accuracy for fatigue life prediction than others. Critical plane approaches treat multiaxial fatigue life predictions as equivalent uniaxial fatigue issues on the critical plane, which connect theory with the physical observation of fatigue cracking behaviour. The stress/strain states of the maximum damage plane are selected as the key parameters of multiaxial fatigue analysis. Thus, the critical plane must be the fatigue damage plane with multiaxial loadings, and the first step is of vital importance to determine the critical plane based on multiaxial loading conditions. The definition of the critical plane can include the maximum damage plane and the maximum shear stress plane, and the definitions of the damage parameters on the critical plane are mostly different combinations of factors including shear stress, normal stress, mean value, amplitude, and maximum of hydrostatic pressure. Figure 1 depicts the process for predicting the fatigue life of a structure by critical plane methods. A brief introduction of the lifetime prediction of the $\omega$-shaped clip is attached as follows:

(1) Through tensile tests of $38 \mathrm{Si} 7$ specimens, the static mechanical properties are obtained, which are utilized for (i) performing elastoplastic finite element 


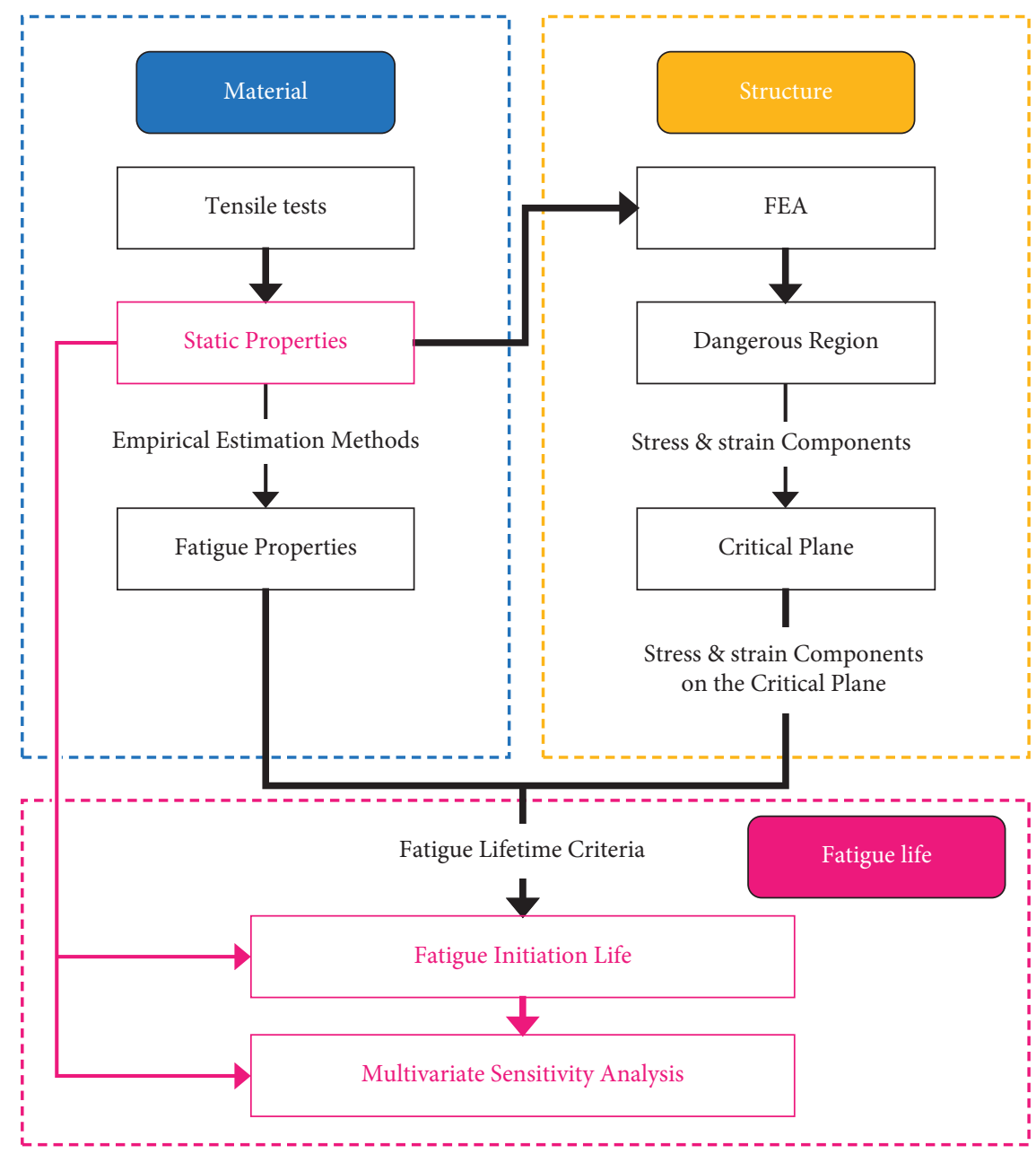

Figure 1: The prediction process for the critical plane method.

analysis (FEA) of the investigated structure and (ii) roughly estimating the fatigue properties of the material based on a selected empirical estimation method.

(2) An elastoplastic FE calculation of the investigated structure is performed, and the results are utilized for (i) determining the dangerous regions according to the stress and strain distributions and (ii) outputting the stress-strain components within the dangerous regions.

(3) The critical plane at the dangerous point is determined via the damage parameters which are obtained by performing three-dimensional (3-D) coordinate transformation according to the 12 stress-strain components.

(4) The fatigue lifetime of the $\omega$-shaped clip is predicted by substituting the fatigue properties of the $38 \mathrm{Si} 7$ material and the damage parameters induced by the multiaxial loading conditions into the selected criterion.

Since the research objective is to analyse the effects of material static mechanical properties on the fatigue crack initiation life of a fastening clip, multivariate sensitivity analysis is then utilized for the entire prediction process. Note that the fatigue crack initiation life of the $\omega$-shaped clip (hereafter called "fatigue life") is emphasized in this paper, and further discussion of fatigue crack propagation is beyond the scope of the paper.

2.1. Tensile Tests. To gain insight into the static mechanical properties of a clip, a series of uniaxial tensile tests were performed on the fastening clip material 38Si7. Because the thermoforming of clips might affect the test results [46], the $38 \mathrm{Si} 7$ material was tested under the following three different conditions: (i) the virgin state in the bar form prior to thermoforming, (ii) the damaged state after a long service life, and (iii) the newly formed state (see Figure 2). The preformed bar was a round bar from which two $25 \mathrm{~mm}$ samples (\#1 and \#2) could be directly sampled. For the formed fastening clips, the two middle legs were removed from the clips by cutting and polishing to meet the experimental requirements (\#3 through \#6).

The tensile tests were conducted using a universal tester SHT4605 (see Figure 3), with a capacity of $600 \mathrm{kN}$ and a maximum speed of $140 \mathrm{~mm} / \mathrm{min}$. The standard ASTM E8 M-16 was adopted as the employed experimental programme. The speeds before and after yielding were set to be 


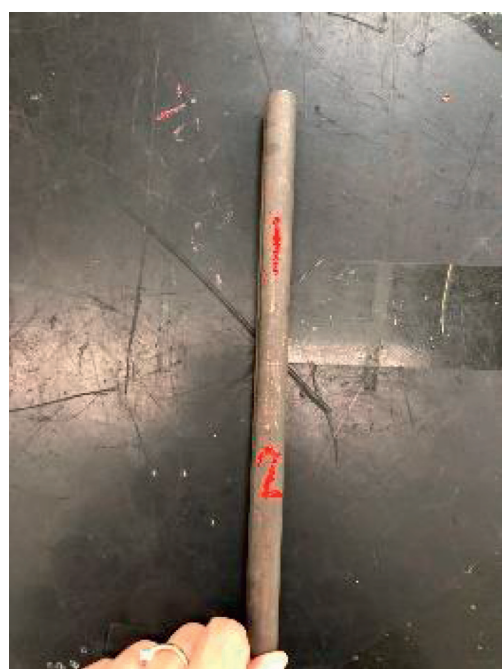

(a)

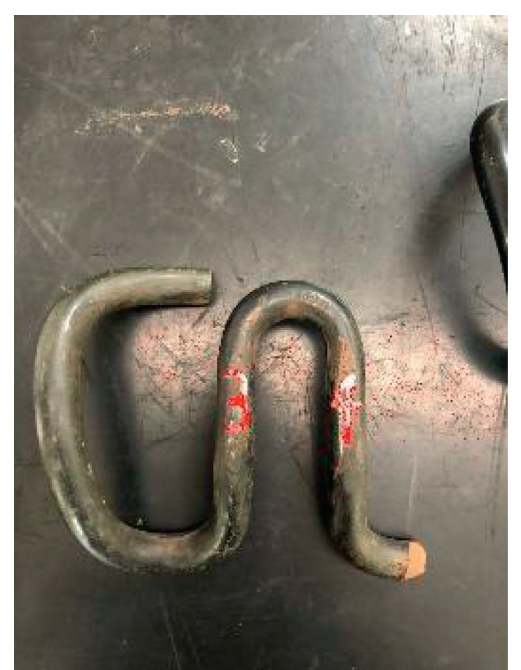

(b)

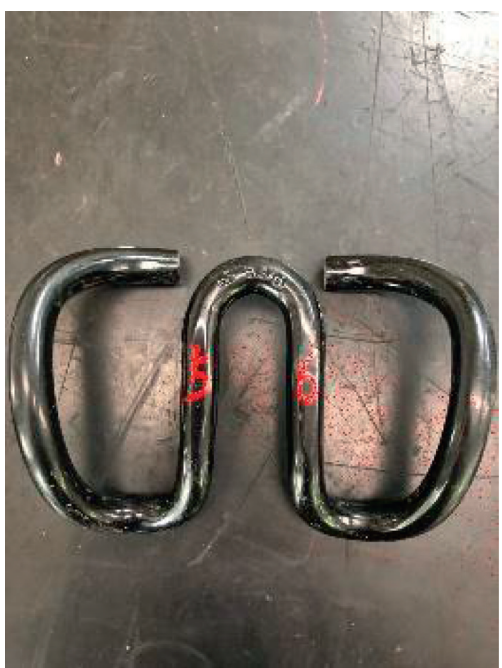

(c)

FIGURE 2: Material specimen of an $\omega$-shaped fastening clip at three different stages: (a) virgin state in the bar form; (b) damaged state after a long service life; (c) newly formed state.

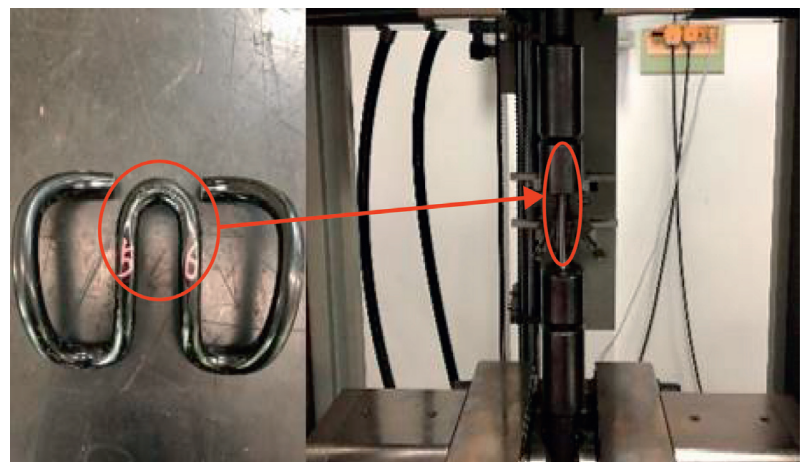

Figure 3: A tensile testing site for the clip material 38Si7.

$1.0 \mathrm{~mm} / \mathrm{min}$ and $24 \mathrm{~mm} / \mathrm{min}$, respectively. All tests were carried out using the displacement-controlled procedure at a controlled ambient temperature so as to eradicate the consideration of any unwanted thermocoupling phenomena. The specimens were marked and clamped at $30 \mathrm{~mm}$ on the top and bottom of the specimen.

The test results were interpreted with respect to the engineering stress-strain curves. The elastic modulus, which was used to quantify the relationship between the tensile stress and axial strain in the linear elastic region, was determined by the slope of the straight curve at the beginning. The yield strength was taken as the stress attaining $0.2 \%$ plastic deformation, whereas the maximum stress on the engineering stress-strain curve was identified as the tensile strength.

2.2. Finite Element Analyses. Taking the Vossloh 300-1 fastener system as the research object, all the components are marked in Figure 4. Among them, the contact relationships between the clip and other parts and the material properties of all the parts are of great importance to the stress-strain

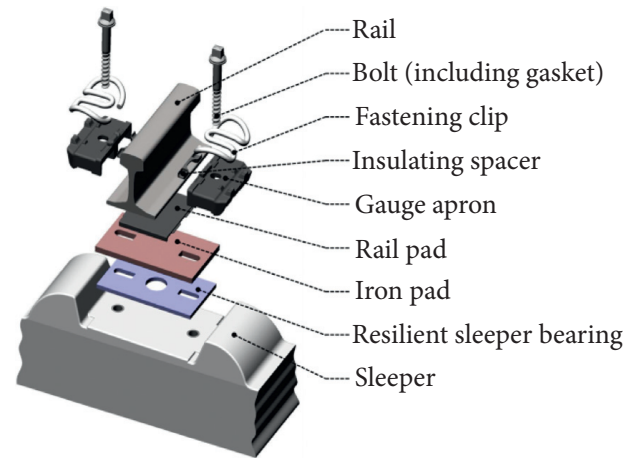

Figure 4: The Vossloh 300-1 fastener system (from the official website of Vossloh LLC).

distributions of the rail clip under normal working conditions, even to the fatigue life prediction of the rail clip. However, many researchers $[2,4-6,13,14]$ established simplified models to save time and costs, in which the crucial importance of the contact relationships in the multiaxial fatigue analysis was ignored. Among the literature studies mentioned in the introduction, the simulation models are too oversimplified to represent the complex situation that includes the in situ stress and strain states inside the fastening clips. In this paper, FEA was performed on an elaborately assembled fastener system by considering all the components and contact pairs, as shown in Figure 5(a). The elastoplastic characteristics of the fastening clip material 38Si7 were determined through the aforementioned tensile tests. The material properties, mesh types, and mesh quantities of the other components are listed in Table 1. In this model, point-to-surface nonlinear contact was created between each toe end of the fastening clips and the corresponding insulating spacer, between each heel end of the fastening clips and the corresponding gauge apron, and between each middle leg of the fastening clips and the 


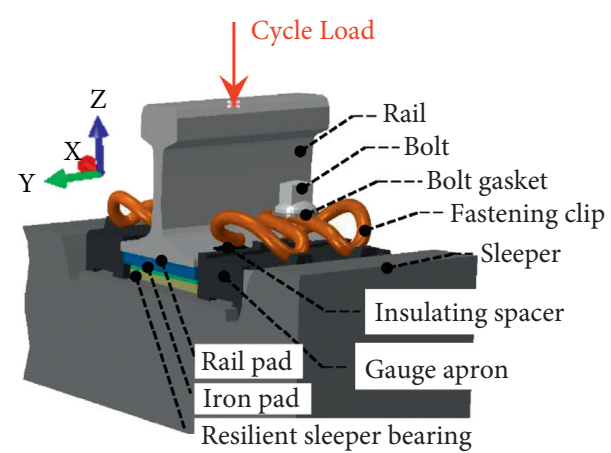

(a)

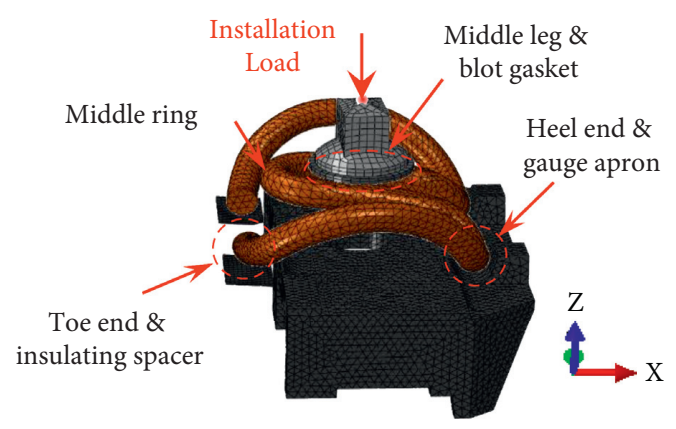

(b)

FIGURE 5: A FE model of the Vossloh 300-1 fastener system: (a) the configuration of the fastener system; (b) locations of the point-to-surface nonlinear contacts.

TABle 1: Material properties, mesh types, and mesh quantities of all components except the clip.

\begin{tabular}{|c|c|c|c|c|c|}
\hline Component & Elastic modulus $(\mathrm{MPa})$ & Poisson's ratio & Density $\left(\mathrm{kg} / \mathrm{m}^{3}\right)$ & Mesh type & Mesh quantity \\
\hline Bolt & 206000 & 0.30 & 7850 & R3D4 & 658 \\
\hline Bolt gasket & 8500 & 0.40 & 1150 & C3D8R & 288 \\
\hline Insulating spacer & 8500 & 0.40 & 1150 & C3D8R & 512 \\
\hline Rail & 200000 & 0.30 & 7850 & R3D4 & 1978 \\
\hline Rail pad & 24.5 & 0.30 & 929 & C3D20 & 3992 \\
\hline Iron pad & 173000 & 0.30 & 7850 & C3D8I & 8168 \\
\hline Resilient sleeper bearing & 19.5 & 0.49 & 870 & C3D20 & 7580 \\
\hline Gauge apron & 8500 & 0.40 & 1150 & $\mathrm{C} 3 \mathrm{D} 10 \mathrm{M}$ & 52533 \\
\hline Sleeper & 34000 & 0.18 & 2500 & R3D4 & 1306 \\
\hline
\end{tabular}

corresponding bolt gasket, as shown in Figure 5(b). The interactions of sliding surfaces were modelled using the basic Coulomb friction model, in which all the coefficients of friction were 0.3 [51]. The nodes for other interactions where the surfaces were close to one another were tied. The longitudinal displacement of the middle ring of the fastening clip ( $y$-direction in Figure 5(b)) was restricted. Due to the complexity of the complete assembly model, the elements of the bolt, rail, and sleeper were simplified and considered part of a rigid body, resulting in faster run times at the model development stage, which could be useful for model verification purposes.

A vertical load of $17 \mathrm{kN}$ ( $F_{\text {installation }}=17 \mathrm{kN}$, minus $z$ direction in Figure 5(b)) was first applied to the upper surface of the bolt, representing a standard installation torque of $250 \mathrm{~N} \cdot \mathrm{m}$ [30]. Then, a cyclic load was applied to the rail head surface, which was simplified from the field-tested wheel-rail force of a high-speed railway (see Figure 6) to the roughly equivalent sinusoidal loading curve, as shown in Figure 7.

The amplitude, mean value, and frequency of the sinusoidal loading curve were calculated with the real-time record of the wheel-rail force curve, following the norm TB/ $\mathrm{T}$ 2489-2016. In addition, another adverse case was considered where the installation load was $19 \mathrm{kN}$, simulating the overload installation torque of $300 \mathrm{~N} \cdot \mathrm{m}$, and the sinusoidal load was amplified (from the magenta solid curve to the green dashed curve in Figure 7), simulating the overload

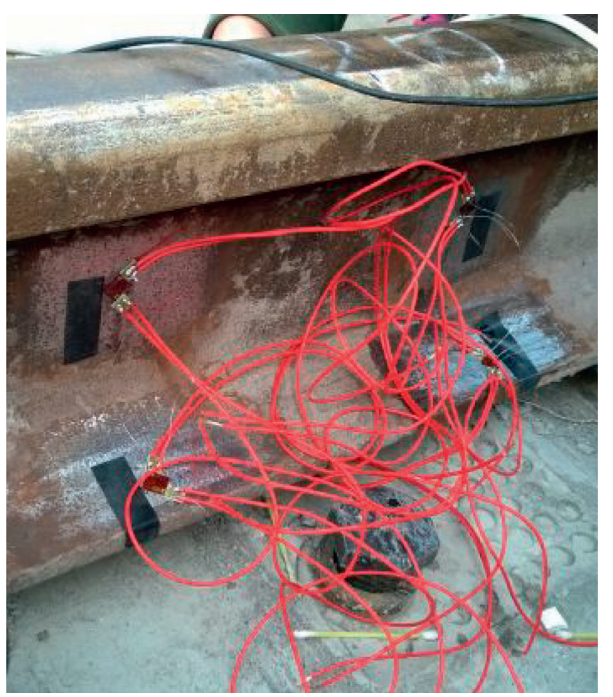

FIGURE 6: A scene from the field tests for the wheel-rail forces of a high-speed railway.

wheel-rail force, normally due to factors such as track irregularities and cornering. Table 2 shows the relevant parameters of the equivalent sinusoidal loads.

2.3. Critical Plane Determination in 3-D Coordinates. As discussed earlier, it is of great importance to identify the 


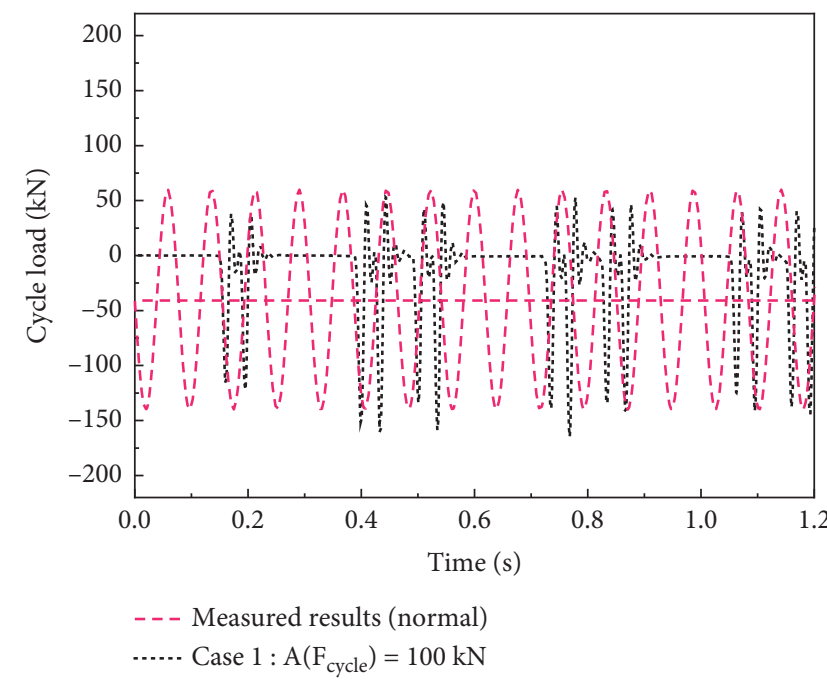

(a)

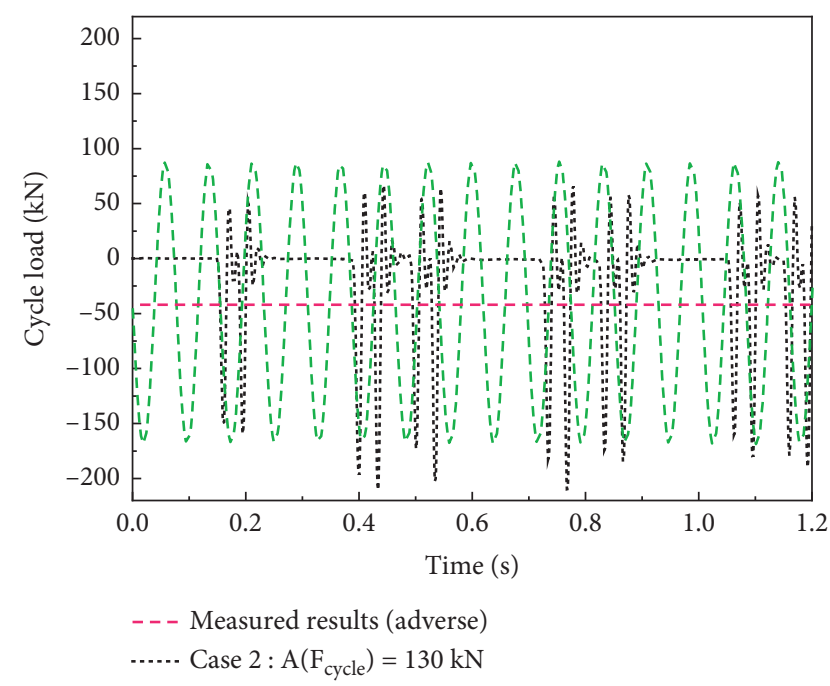

(b)

FIgURE 7: Measured wheel-rail forces and corresponding equivalent sinusoidal loads in the FE calculations. (a) Case 1. (b) Case 2.

TABLE 2: Parameters related to installation loads and cycle loads in the FEA.

\begin{tabular}{lcccc}
\hline Case & $\begin{array}{c}\text { Installation } \\
\text { load } \\
F_{\text {installation }}(\mathrm{kN})\end{array}$ & $\begin{array}{c}\text { Amplitude } \\
A\left(F_{\text {cycle }}\right)\end{array}$ & $\begin{array}{c}\text { Mean value } \\
\text { Avg }\left(F_{\text {cycle }}\right) \\
(\mathrm{kN})\end{array}$ & $\begin{array}{c}\text { Frequency } \\
f(\mathrm{~Hz})\end{array}$ \\
\hline Case 1 & 17 & 100 & -40 & 4 \\
Case 2 & 19 & 130 & & 4 \\
\hline
\end{tabular}

critical plane at the critical point, that is, the plane of the crack at the critical position. Based on the classic theory of elasticity for 3-D space problems [52], 3-D principal strains and three maximum shear strains can first be determined at the critical point in the global coordinate system. Then, via the coordinate transformation matrix of direction cosines, the specific plane of the maximum principal strain/shear strain can be identified.

Assuming that there is one principal strain $\varepsilon_{i}$ at critical point $\mathbf{D}$ on plane $\mathbf{S}$ and taking any plane $\mathbf{A B C}$ parallel to $\mathbf{S}$ near point $\mathbf{D}$, a small tetrahedron is formed in the global coordinate system that passes through critical point $\mathbf{D}$ (see Figure 8).

When the tetrahedron is infinitely small and approaches point $\mathbf{D}$, the strain on plane $\mathbf{A B C}$ is the strain on plane $\mathbf{S}$ where point $\mathbf{D}$ is located, namely, the principal strain. Assuming that the outer normal of plane $\mathbf{A B C}$ is $\mathbf{O N}$, the projection of $\mathbf{O N}$ on the $x$-y-plane forms an angle $\theta$ with the $x$-axis, and the angle between $\mathbf{O N}$ and the $x-y$-plane is $\phi$ (see Figure 8). The direction cosines of plane ABC are expressed as follows:

$$
\begin{aligned}
l & =\cos \theta \cos \phi, \\
m & =\sin \theta \cos \phi \\
n & =\sin \phi l^{2}+m^{2}+n^{2}=1 .
\end{aligned}
$$

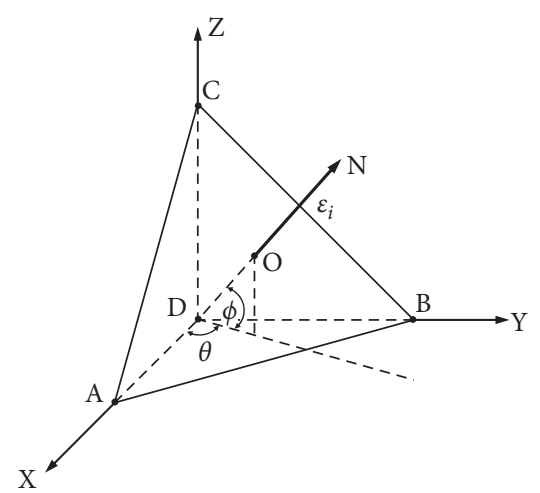

FIGURE 8: Principal strain $\varepsilon_{i}$ and its direction $\mathbf{O N}$ at critical point $\mathbf{D}$.

Each component of the global strain on plane $\mathrm{ABC}$ in the global coordinate system is therefore represented as follows:

$$
\left\{\begin{array}{l}
l \varepsilon_{x}+m \frac{\gamma_{y x}}{2}+n \frac{\gamma_{z x}}{2}=l \varepsilon_{i} \\
l \frac{\gamma_{x y}}{2}+m \varepsilon_{y}+n \frac{\gamma_{z y}}{2}=m \varepsilon_{i} \\
l \frac{\gamma_{x z}}{2}+m \frac{\gamma_{y z}}{2}+n \varepsilon_{z}=n \varepsilon_{i} .
\end{array}\right.
$$

By solving two simultaneous equations (1) and (2), the direction and the plane of each principal strain $\varepsilon_{i}$ can be identified, and a coordinate system based on the directions of the 3 -D principal strains $\varepsilon_{1}, \varepsilon_{2}$, and $\varepsilon_{3}$ can be defined. By rotating the new coordinate system $45^{\circ}$, the direction and plane of the local maximum shear strain can also be identified.

The direction cosines of the new 3-D system $\left(X^{\prime} Y^{\prime} Z^{\prime}\right)$ based on the original coordinate system (XYZ) are expressed as follows: 


$$
\begin{aligned}
& l_{x_{1} x}=\cos \theta \cos \phi, l_{x_{1} y}=\sin \theta \cos \phi, l_{x_{1} z}=\sin \phi \\
& l_{y_{1} x}=-\sin \theta, \quad l_{y_{1} y}=\cos \theta, \quad l_{y_{1} z}=0, \\
& l_{z_{1} x}=-\cos \theta \sin \phi, \quad l_{z_{1} y}=-\sin \theta \sin \phi, \quad l_{z_{1} z}=\cos \phi .
\end{aligned}
$$

Hence, the strain components in the new coordinate system are represented by the direction cosine matrix as follows:

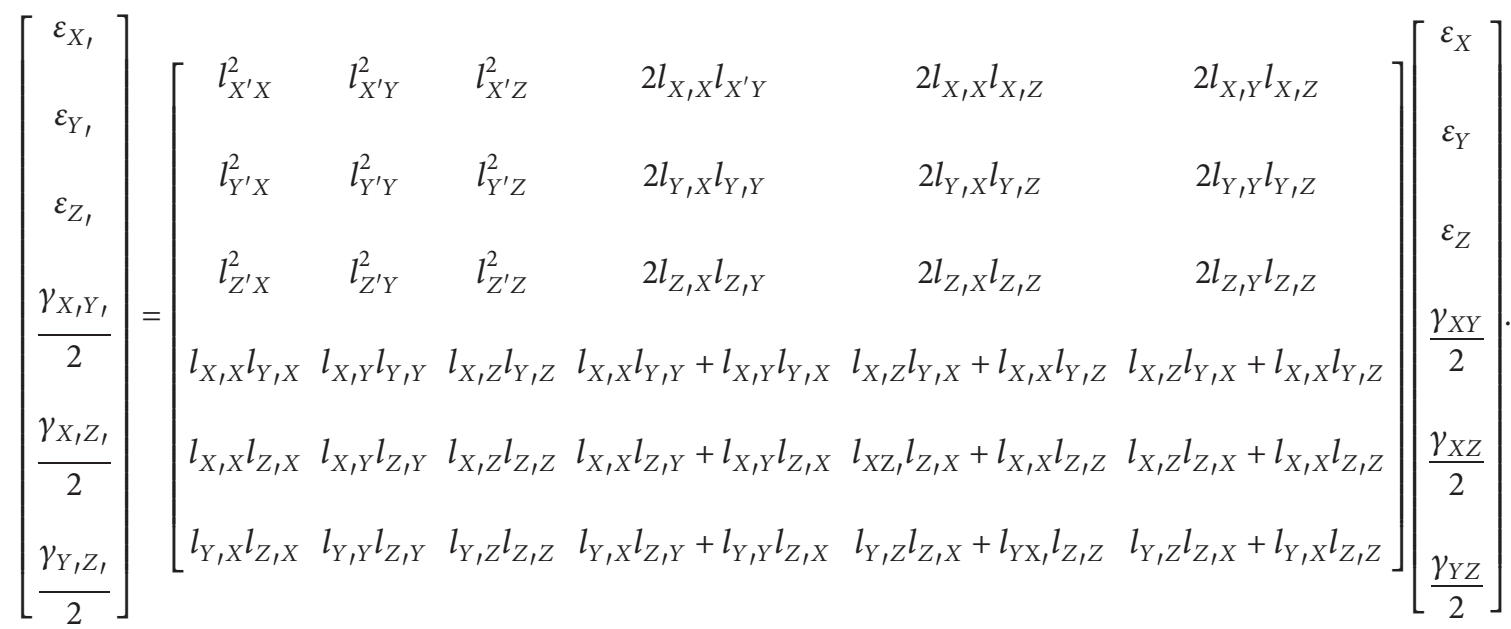

2.4. Brown-Miller Criterion and Seeger's Method. The strainbased critical plane method was first proposed by Brown, Miller, and Findley [40]. They considered that a combination of shear strain and normal strain acting on the maximum shear strain plane was responsible for crack initiation and growth. The authors reported that fatigue crack initiation depended on the maximum shear strain $\gamma_{\max }$ and normal strain range $\Delta \varepsilon_{n}$ in the maximum shear strain plane. However, their criterion failed to consider the effect of mean stress on the fatigue life. In order to overcome this shortcoming, the Morrow mean-stress-correction method was then employed to correct the mean stress $\sigma_{m}$, and they proposed the following formula with two model parameters:

$$
\begin{aligned}
\gamma_{\max }+\Delta \varepsilon_{n} & =C_{1} \frac{\sigma_{f}^{\prime}-\sigma_{m}}{E}(2 N)^{b}+C_{2} \varepsilon_{f}^{\prime}(2 N)^{c}, \\
C_{1} & =1+v_{e}+\frac{\left(1-v_{e}\right)}{2}, \\
C_{2} & =1+v_{p}+\frac{\left(1-v_{p}\right)}{2},
\end{aligned}
$$

where $\sigma_{f}^{\prime}$ and $b$ represent the fatigue strength coefficient and index of the material, respectively; $\varepsilon_{f}^{\prime}$ and $c$ are the fatigue ductility coefficient and index of the material, respectively; $\nu_{e}$ and $\nu_{p}$ represent the elastic value and the plastic value of Poisson's ratio, respectively; $E$ is the elastic modulus; and $N$ is the number of cycles to failure. The left side denotes the shear strain and normal strain amplitudes in the plane of maximum shear strain at the critical point. The right side denotes the elastic strain component and the plastic component related to the effect of complex multiaxial loading.
In addition to the damage parameters obtained from FEA, the fatigue properties can generally be obtained by fitting strain-control experimental data or roughly estimated based on empirical estimation methods such as four-point correlation [53], universal slopes [53], and Seeger's method [54]. To determine the fatigue properties of 38Si7, Seeger's method, which is normally used for estimating the fatigue properties of plain carbon steel, middle-low alloy steel, aluminium alloy, and titanium alloy, was employed. The estimation formula is as follows:

$$
\begin{aligned}
\sigma_{f}^{\prime} & =1.5 \sigma_{b}, \\
\varepsilon_{f}^{\prime} & =0.59 a, \\
b & =-0.087, \\
c & =-0.58,
\end{aligned}
$$

where $a$ is a model coefficient, related to the tensile strength $\sigma_{b}$ and elastic modulus $E$ of the investigated material: $a=1$ when $\sigma_{b} / E<0.003$, whereas $a=1.375-125 \sigma_{b} / E$ when $\sigma_{b} / E \geq 0.003$.

Note that the material properties required from the fatigue life prediction model are the static mechanical properties including Poisson's ratio and the elastic modulus and the fatigue properties which are estimated from the elastic modulus and the tensile strength based on Seeger's method. Therefore, the material static mechanical properties required are mainly Poisson's ratio, elastic modulus, and tensile strength. Since Poisson's ratio of metallic material is nearly unchanged with an ignorable variation, this paper focused on the effects of the elastic modulus and tensile strength of the material on the fatigue crack initiation life of a fastening clip. 
2.5. Multivariate Sensitivity Analysis. To evaluate the sensitivity of the static mechanical properties of $38 \mathrm{Si} 7$ to the fatigue crack initiation life of a fastening clip, the sensitivity functions and sensitivity factors proposed by Zhang and Zhu [55] were employed. Based on univariate sensitivity analysis, Zhang and Zhu proposed sensitivity functions and sensitivity factors for multivariate sensitivity analysis. The authors successfully identified the variable that most affected the horizontal deformation of the high sidewall of an underground power plant in the Laxiwa underground project. Cheng [56] also used this method to analyse the sensitivity of the material static mechanical properties of $\mathrm{W} 6 \mathrm{Mo} 5 \mathrm{Cr} 4 \mathrm{~V} 2$ steel to the fatigue crack initiation life of a drive shaft. He found that the fatigue crack initiation life of the drive shaft was extremely sensitive to the elastic modulus, yield strength, and tensile strength. In the multivariate sensitivity analysis, the first step is to find the functional relationships between the material static mechanical properties and the fatigue crack initiation life. This step consists of building a system model $N_{f}=f\left(x_{1}, x_{2}, \ldots, x_{n}\right)$ based on the above fatigue crack initiation life prediction method, calculating the effect of each material static property $\left(x_{1}, x_{2}, \ldots, x_{n}\right)$ on the fatigue crack initiation life $N_{f}$ of the fastening clip, and thereby obtaining the fatigue crack initiation life of the fastening clip as a function of each material static property.

Then, a dimensionless parameterization was performed for each parameter, and the dimensionless sensitivity function $S\left(x_{i}\right)$, i.e., the ratio of the relative error of the fatigue crack initiation life to the relative error of the material static property, was calculated as follows:

$$
\begin{aligned}
S\left(x_{i}\right)=\left(\frac{\left(\left|\Delta N_{f}\right| / N_{f}\right)}{\left(\left|\Delta x_{i}\right| / x_{i}\right)}\right)=\left|\frac{\Delta N_{f}}{\Delta x_{i}}\right| \frac{x_{i}}{N_{f}} & \cong\left|\frac{d N_{f}}{d x_{i}}\right| \frac{x_{i}}{N_{f}}, \\
i & =1,2, \ldots, n .
\end{aligned}
$$

When using the value of $x_{i}$ as the reference material static property $x_{i}^{*}$, the function $S\left(x_{i}^{*}\right)$ is the sensitivity factor of the material static property. The larger the value of $S\left(x_{i}^{*}\right)$ is, the more sensitive the fatigue crack initiation life is to the material static property.

\section{Results and Discussion}

3.1. Test Results of the Clip Material 38Si7. The engineering stress-strain curves of the fastening clip material at different states were obtained, as shown in Figure 9. The test results of each pair of samples in the same stage (in the same colour but with different symbols) show a perfect agreement with each other, indicating that the test results were repeatable with high confidence. The curves for the damaged clip samples after a long service life (samples \#3 and \#4) are nearly the same as those in the newly formed state (samples \#5 and \#6), whereas the results for the bar before clip formation (samples \#1 and \#2) are slightly higher. Table 3 lists the mean values of the static mechanical properties. The comparison of the test results shows that the tensile strength, yield strength, and elastic modulus of the material for the

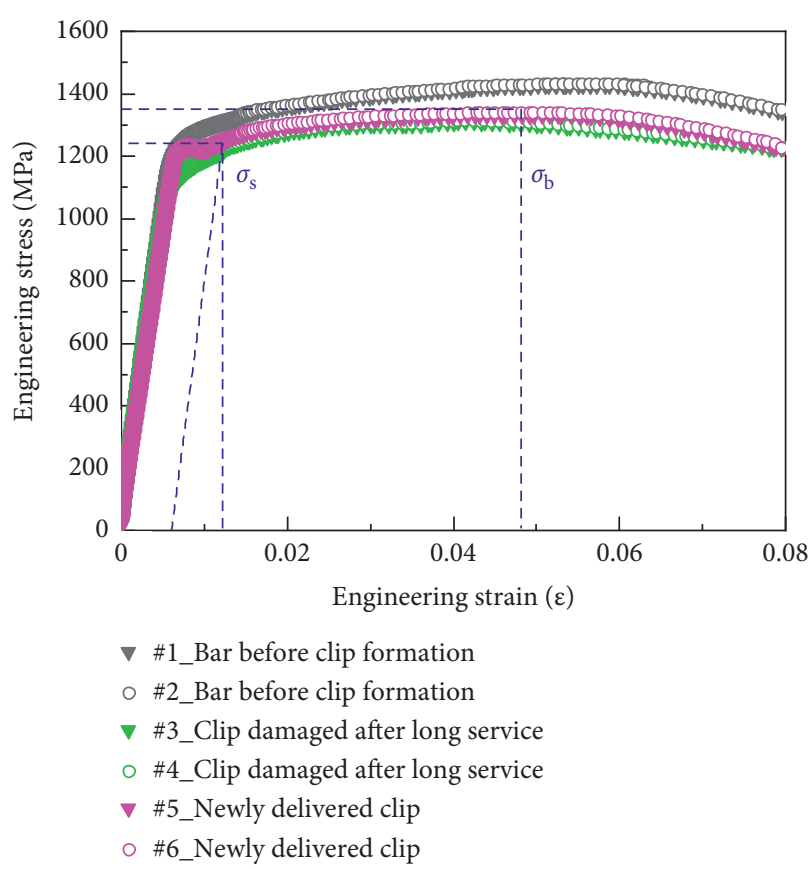

FIgure 9: The uniaxial tensile test results on the clip material 38Si7 (engineering stress-strain curve).

TABle 3: Tensile properties of the clip material 38Si7 (mean values).

\begin{tabular}{lccc}
\hline Sample & $\begin{array}{c}\text { Tensile strength } \\
\sigma_{\mathrm{b}}(\mathrm{MPa})\end{array}$ & $\begin{array}{c}\text { Yield strength } \\
\sigma_{s}(\mathrm{MPa})\end{array}$ & $\begin{array}{c}\text { Elastic modulus } \\
E(\mathrm{GPa})\end{array}$ \\
\hline$\# 1 / \# 2$ & 1425 & 1254 & 190 \\
$\# 3 / \# 4$ & 1349 & 1230 & 180 \\
$\# 5 / \# 6$ & 1350 & 1242 & 180 \\
\hline
\end{tabular}

fastening clip remain nearly constant in different states. The static mechanical properties of the material were not directly affected by the thermoforming process of the fastening clip, and deformations occurred during the in-service process. Based on the tensile properties, the fatigue properties of the fastening clip material were obtained through the Seeger algorithm, as shown in Table 4. Compared with the samples of the bars before clip formation (samples \#1 and \#2), the samples of newly delivered clips (samples \#5 and \#6) had slightly lower tensile strength, yield strength, and elastic modulus values. Moreover, the damage during long service periods (samples \#3 and \#4) had no effect on the tensile properties.

3.2. FEA Results. The static mechanical properties of newly formed clips (samples \#5 and \#6) were considered in the FEA for the following two reasons. One, the model was a fastening clip rather than a bar before clip formation. Two, another was that the static mechanical properties of the fastening clip material for the clip damaged after a long service life were nearly the same as those of the newly delivered clip.

In the FE calculations, the stress and strain distributions of the fastening clips in case 1 and case 2 were successively determined, as shown in Figure 10. The global maximum 
TABLE 4: Fatigue properties of the fastening clip material.

\begin{tabular}{lcccc}
\hline Sample & $\begin{array}{c}\text { Fatigue strength } \\
\text { coefficient } \sigma_{f}^{\prime}(\mathrm{MPa})\end{array}$ & $\begin{array}{c}\text { Fatigue strength } \\
\text { exponent } b\end{array}$ & $\begin{array}{c}\text { Fatigue ductility } \\
\text { coefficient } \varepsilon_{f}^{\prime}\end{array}$ & $\begin{array}{c}\text { Fatigue ductility } \\
\text { exponent } c\end{array}$ \\
\hline$\# 1 / \# 2$ & 2138 & & 0.2581 & -0.58 \\
$\# 3 / \# 4$ & 2024 & -0.087 & 0.2585 & \\
$\# 5 / \# 6$ & 2025 & & 0.2581 & \\
\hline
\end{tabular}

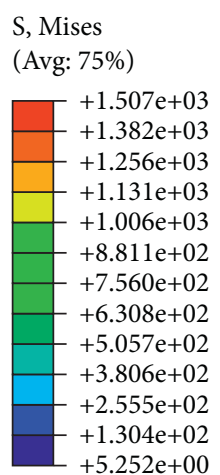

S, Mises

(Avg: $75 \%)$
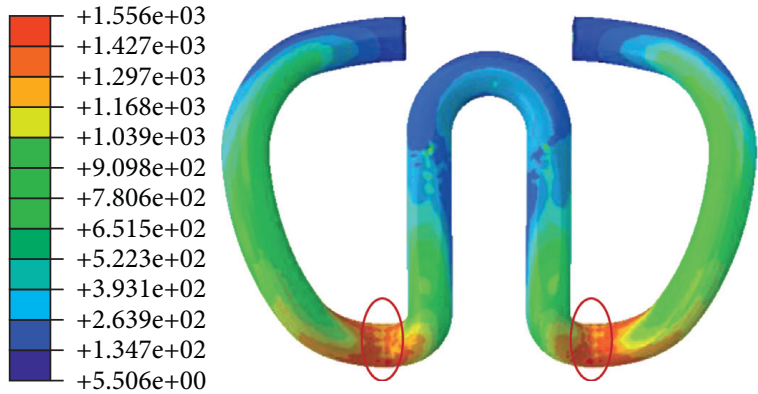

(c)

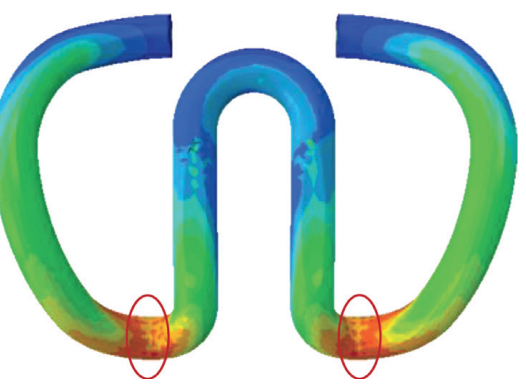

(a)
LE, Max. Principal

(Avg: $75 \%$ )

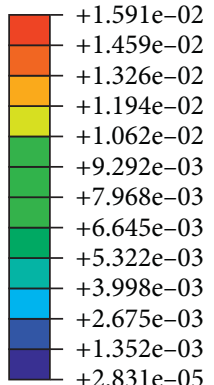

$+2.831 \mathrm{e}-05$

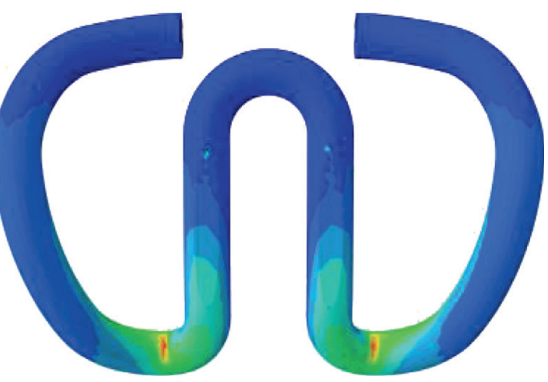

(b)

LE, Max. Principal (Avg: $75 \%$ )
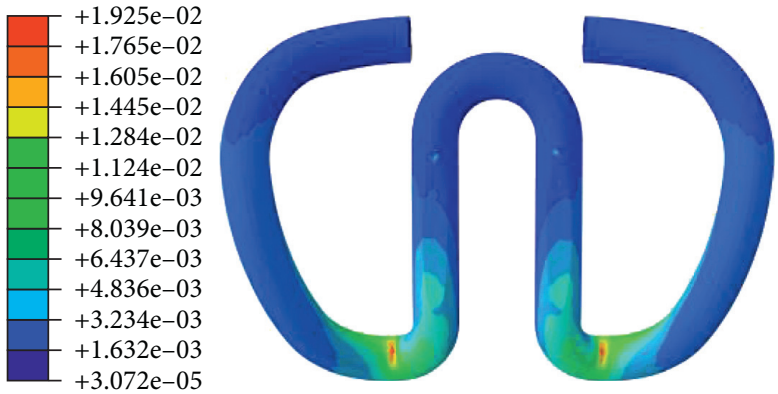

(d)

Figure 10: Stress/strain distributions of the fastening clip in FEA: (a) von Mises stress distribution for case 1; (b) maximum principal strain distribution for case 1; (c) von Mises stress distribution for case 2; (d) maximum principal strain distribution for case 2.

stress of the fastening clip is $1507 \mathrm{MPa}$ for case 1 and $1556 \mathrm{MPa}$ for case 2, occurring at the inner side of the small arc at the heel end (see the red circles in Figure 10).

The maximum von Mises stress, in either case, was located at node 20888 of the FE model. Six stress components are shown in Table 5. Some stress components were beyond the fatigue limit of the material. The maximum principal strain was $15901.72 \mu \varepsilon$ for case 1 and $19156.69 \mu \varepsilon$ for case 2, which was also observed at node 20888 of the fastening clip. These strain components are shown in Table 6. The global maximum stress was extremely high, far beyond the fatigue limit of the material and even beyond the measured yield strength of the material, indicating that the elastoplastic stage was achieved under the actual load during operation, and it was prone to fatigue failure. Hence, the fatigue failure developed in the fastening clip was mainly due to the local deformation concentration of the material, and the inner side of the small arc at the heel end was the dangerous region.
TABle 5: Stress components at the critical point (unit: MPa).

\begin{tabular}{cccccccc}
\hline Node & Case & $\sigma_{x}$ & $\sigma_{y}$ & $\sigma_{z}$ & $\tau_{x y}$ & $\tau_{x z}$ & $\tau_{y z}$ \\
\hline \multirow{2}{*}{208888} & Case 1 & 379.42 & 74.07 & -178.10 & -670.96 & 151.10 & 246.98 \\
& Case 2 & 398.82 & 79.18 & -178.62 & -678.88 & 145.72 & 255.30 \\
\hline
\end{tabular}

3.3. Fatigue Crack Initiation Life Predictions. By performing 3-D coordinate transformation, three principal strains and three local maximum shear strains at the critical point were calculated, as listed in Table 7. The maximum shear strain, in either case, is nearly twice as high as the maximum principal strain. The directions and the planes of the maximum principal strain $\varepsilon_{1}$ and maximum shear strain $\gamma_{1}$ can also be identified, as shown in Figure 11. Figure 12 shows the actual fracture plane of the fastening clip. The comparison of these figures shows that, at the critical point, the actual fastening clip is particularly prone to developing cracks on the plane of the maximum shear strain, and the maximum shear strain initiates the fatigue cracks. Moreover, the tensile strain in the 
TABLE 6: Strain components at the critical point (unit: $\mu \varepsilon$ ).

\begin{tabular}{lccccccc}
\hline Node & Case & $\varepsilon_{x}$ & $\varepsilon_{y}$ & $\varepsilon_{z}$ & $\gamma_{x y}$ & $\gamma_{x z}$ \\
\hline \multirow{2}{*}{20888} & Case 1 & 5896.66 & -175.80 & -4986.65 & -25381.00 & 6029.26 \\
& Case 2 & 7250.67 & -343.09 & -6109.37 & -30503.10 & 6865.56 & 10136.30 \\
& & &
\end{tabular}

TABLE 7: Three principal strains and three local maximum shear strains at the critical point (unit: $\mu \varepsilon$ ).

\begin{tabular}{lccccccc}
\hline \multirow{2}{*}{ Node } & Case & $\varepsilon_{1}$ & $\varepsilon_{2}$ & $\varepsilon_{3}$ & $\gamma_{1}$ & $\gamma_{2}$ \\
\hline \multirow{2}{*}{20888} & Case 1 & 15901.72 & -1175.59 & -13991.92 & 29848.86 & 17089.25 & 12759.61 \\
& Case 2 & 19156.69 & -1453.70 & -16904.78 & 36132.87 & 20753.20 & 15379.67 \\
\hline
\end{tabular}

plane accelerates the accumulation of crack damage. Therefore, the damage could be reasonably represented as a function of both the shear strain and the strain normal to this plane. The Brown-Miller criterion was ideally suited for predicting the fatigue life of a fastening clip.

By substituting the material fatigue properties and the damage parameters into the Brown-Miller criterion, the fatigue lives of the fastening clips for cases 1 and 2 were predicted, and the distribution contours are shown in Figure 13. Under normal in-service conditions, the lowest fatigue life of the fastening clip was approximately 180 million times (i.e., infinite life), occurring in the heel end area. For case 2, the lowest fatigue life was only approximately 2.399 million times, which is lower than the limit of the requirement before use ( 5 million times).

However, the actual in-service condition of the fatigue life was even worse due to the addition of the broadband minor-amplitude excitation induced by track irregularities and rail corrugation [57-61]. The typical practice employed to improve this adverse condition is to grind the rail profiles [61] or decrease the train speeds [62]. These measures severely impede the development of high-speed railway traffic. However, in this paper, the solution proposed is to improve the material performance at the design stage of a fastening clip. Based on this idea, the effects of the material static mechanical properties on the fatigue life of a fastening clip were discussed according to these in-service conditions.

\subsection{Effect of the Material Static Mechanical Properties.} According to relevant studies $[1,2,4,8,11,12,17,20]$, the elastic modulus of the fastening clip material is between $150 \mathrm{GPa}$ and $300 \mathrm{GPa}$, and its tensile strength is normally within the range of $1000-1600 \mathrm{MPa}$. Therefore, the values of the elastic modulus and tensile strength in these ranges could be used to analyse their effects on the fatigue crack initiation life of the fastening clip. The calculations were performed following the aforementioned method.

Figure 14 shows that the fatigue lives of the fastening clips vary with the elastic modulus of the material. The increase in the elastic modulus leads to the shortening of the fastening clip fatigue life, and the effect gradually weakens as the elastic modulus increases. The fatigue life for case 1 is beyond the allowable limit of 5 million times only when the elastic modulus is lower than $250 \mathrm{GPa}$. However, compared

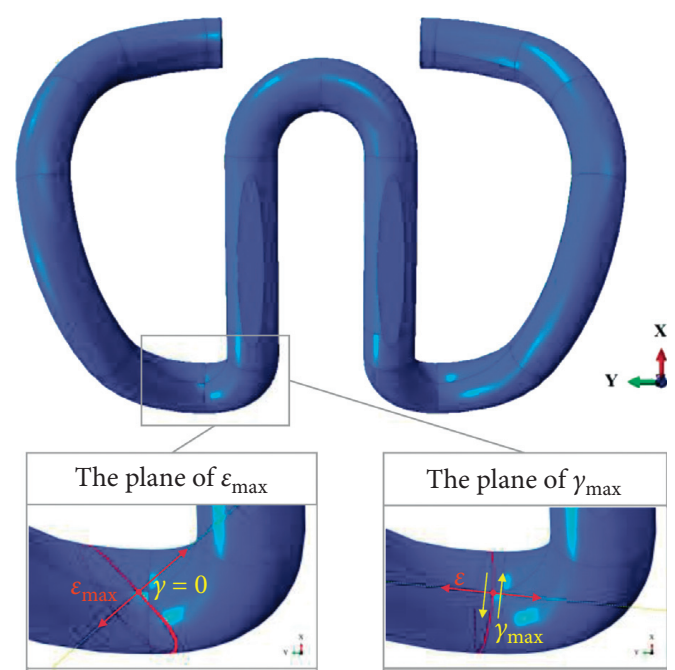

FIGURE 11: Simulated fracture planes of a fastening clip.

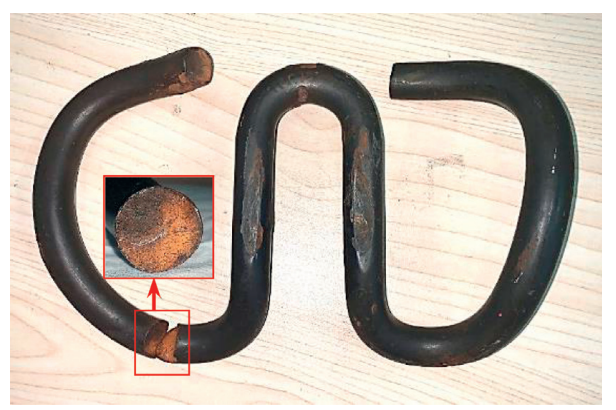

Figure 12: The actual fracture plane of a fastening clip.

with the fatigue life for case 1 in each elastic modulus (magenta rectangular symbols), the fatigue life for case 2 (yellow triangle symbols) is much lower. In such a case, to guarantee that the fastening clip conforms to the requirements before use, the elastic modulus of the material must be at least lower than $160 \mathrm{GPa}$ (i.e., lower than the reference value).

The effects of the material tensile strength on the fastening clip fatigue life for the two cases are shown in Figure 15. The fastening clip fatigue life increases with increasing material tensile strength. The fatigue life for case 1 


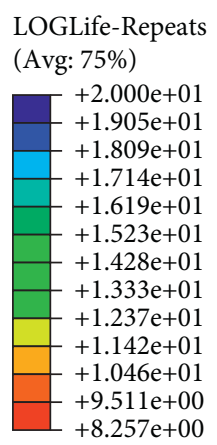

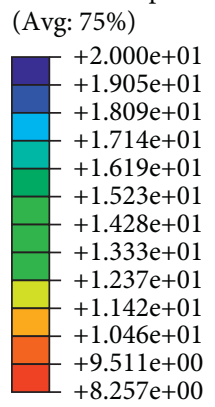

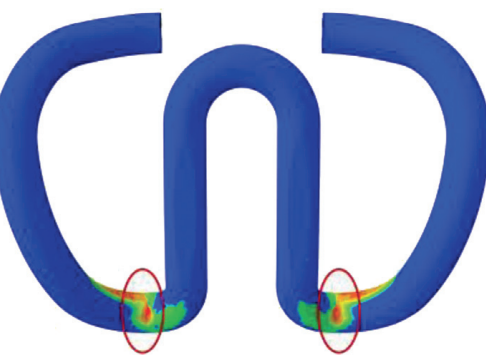

(a)
LOGLife-Repeats (Avg: 75\%)
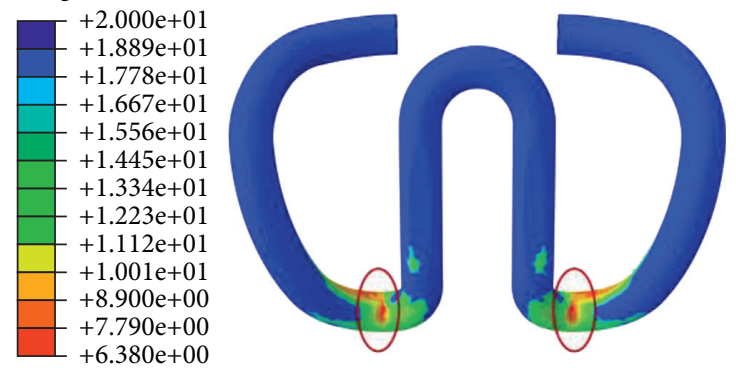

(b)

FIgure 13: Fatigue crack initiation lives of the $\omega$-shaped fastening clips: (a) case 1 and (b) case 2.

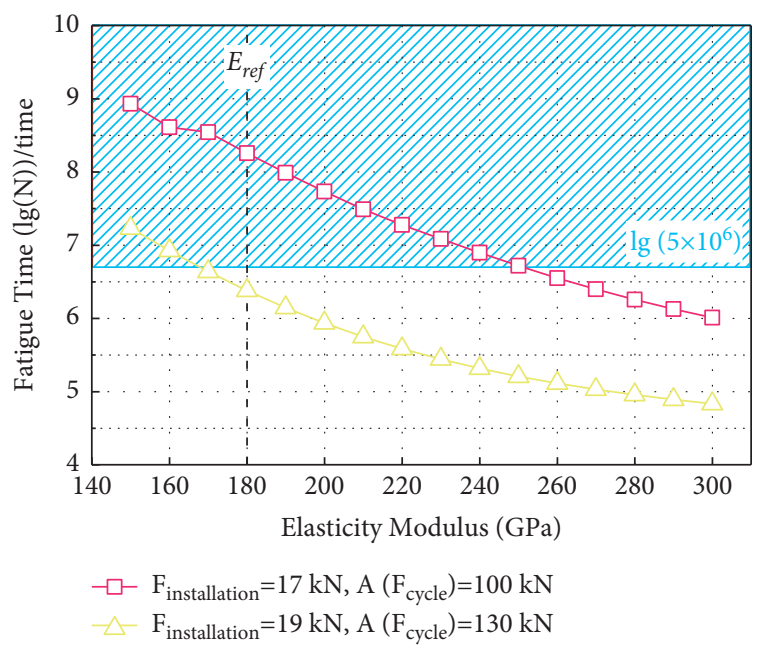

FIGURE 14: Variations in the fastening clip fatigue life with elastic modulus of the material.

is beyond the allowable limit of 5 million times only when the tensile strength is higher than $1150 \mathrm{MPa}$. However, the fatigue life for case 1 for each tensile strength (megenta rectangular symbols) is much higher than that for case 2 (yellow triangle symbols). In such a case, to guarantee that the fastening clip conforms to the requirements before use, the elastic modulus of the material must exceed $1450 \mathrm{MPa}$ (i.e., higher than the reference value).

As shown in Table 8, the sensitivity factors of the elastic modulus and tensile strength of the fastening clip material were calculated based on the definition of the sensitivity factor in equation (7). The sensitivity factor of the elastic modulus in each case is approximately 10, whereas that of the tensile strength in each case is much higher, with a value of approximately 15. With the worse in-service condition of the fastening clip (from case 1 to case 2), the sensitivity factor of each material performance parameter slightly decreases, i.e., from 10.09 to 9.89 and from 16.29 to 15.05 , respectively.

The sensitivity analysis indicates that the fatigue crack initiation life of the fastening clip is extremely sensitive to the elastic modulus, especially more sensitive to the tensile

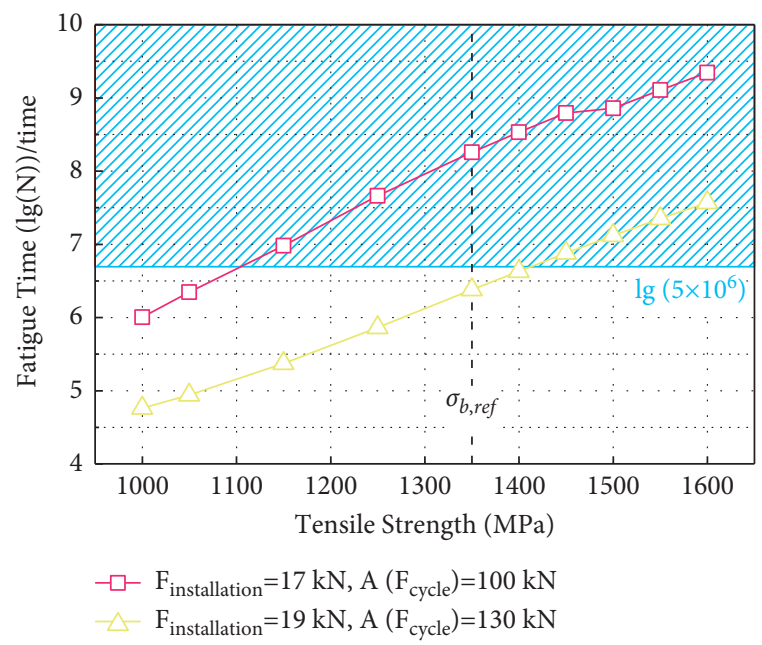

FIgURE 15: Variations in the fastening clip fatigue life with the tensile strength of the material.

TABLe 8: Sensitivity factors $S\left(x_{i}^{*}\right)$ of the material static mechanical properties $x_{i}^{*}$.

\begin{tabular}{lcc}
\hline $\begin{array}{l}\text { Material performance } \\
\text { parameter } x_{i}^{*}\end{array}$ & $\begin{array}{c}\text { Elastic } \\
\text { modulus }(E)\end{array}$ & $\begin{array}{c}\text { Tensile } \\
\text { strength }\left(\sigma_{b}\right)\end{array}$ \\
\hline $\begin{array}{l}\text { Case } 1 \\
F_{\text {installation }}=17 \mathrm{kN}\end{array}$ & 10.09 & 16.29 \\
$A\left(F_{\text {cycle }}=100 \mathrm{kN}\right)$ & & \\
Case 2 & & \\
$F_{\text {installation }}=19 \mathrm{kN}$ & 9.89 & 15.05 \\
$A\left(F_{\text {cycle }}=130 \mathrm{kN}\right)$ & & \\
\hline
\end{tabular}

strength. For example, the sensitivity factor $S\left(x_{i}\right)$ of the elastic modulus $E$ is approximately 15 , which means that the change in fatigue life $\left(\left|\Delta N_{f} / N_{f}\right|\right)$ is 15 times the change in the material static mechanical properties $\left(\left|\Delta x_{i} / x_{i}\right|\right)$, according to (7). That is, the fastening clip fatigue life can be increased significantly by $80 \%$ when the elastic modulus of the fastening clip material decreased by only $6 \%$. The elastic modulus and tensile strength of the fastening clip material have marked effects on the fatigue life of the fastening clip, which is of great significance in the reverse design of the fastening clip. 
Since it is difficult to reduce the elastic modulus of a raw material through conventional heat treatments and alloying techniques $[24,26]$, increasing the tensile strength of the material can be employed as an alternative means to improve the fatigue resistance of fastening clips. However, when the tensile strength is excessively high, the plasticity and fracture toughness of the material decreases as the tensile strength increases, which makes the fastening clip more prone to brittle failure [63]. From an engineering viewpoint, it is suggested that the tensile strength of the clip material should be properly improved to at least $1450 \mathrm{MPa}$.

\section{Conclusions}

Based on the measured elastoplastic characteristics of the fastening clip material, i.e., 38Si7, through a series of uniaxial tensile tests, this paper performed FEA on the complete assembly system of a fastening clip to determine the location of the dangerous region. By applying the critical plane method, the critical plane was determined. Then, the fastening clip fatigue lives in two cases were predicted following the Brown-Miller criterion. The effects of the material static mechanical properties on the fatigue life of the fastening clip were analysed, as was the sensitivity of the fatigue life to those parameters. The following conclusions can be drawn:

(1) The initiation and progression of fatigue cracks in a fastening clip occur in the plane where the maximum shear strain is included. The Brown-Miller criterion is properly employed in predicting the initiation and progression of fatigue cracks in a fastening clip and predicting the fatigue life.

(2) The material static mechanical properties of a fastening clip not only affect the stress/strain components of the fastening clip but also determine the fatigue static mechanical properties of the material. The static mechanical properties of the material have marked effects on the fatigue life of a fastening clip, which is of great significance in the reverse design of a fastening clip.

(3) The fatigue crack initiation life of a fastening clip could be improved by increasing the tensile strength of the fastening clip material to at least $1450 \mathrm{MPa}$ by optimizing the metal element ratios or heat treatment of the metal. If the technical conditions permit, the elastic modulus could also be appropriately reduced to no more than $160 \mathrm{GPa}$.

\section{Data Availability}

The data used to support the findings of this study are available from the corresponding author upon request.

\section{Conflicts of Interest}

The authors declare that there are no conflicts of interest regarding the publication of this paper.

\section{Acknowledgments}

The authors acknowledge the support of the Metal Testing Laboratory of Shanghai Research Institute of Materials. The financial support provided by the research sponsors through CREEC and the inspiring discussion with Dr. Yang are deeply appreciated and acknowledged. This research was funded by the Shanghai Rising-Star Program (19QB1401100) and Shanghai Pujiang Program (20PJ1417300).

\section{References}

[1] H. Xiao, C. Ma, and X. Guo, "Fractures of e-type fastening clip by spectral analysis method," Journal of Tongji University, vol. 45, 2017.

[2] S. Y. Zhu, C. B. Cai, and Q. Yin, "Dynamic analysis of rail fastening clip in high-speed railway," Engineering Mechanics, vol. 30, 2013.

[3] A. Hasap, P. Paitekul, N. Noraphaiphipaksa, and C. Kanchanomai, "Analysis of the fatigue performance of elastic rail clip," Engineering Failure Analysis, vol. 92, 2018.

[4] W. Qi, Y. Liu, J. Chen, Z. Zhao, and C. Li, "Quasi-static analysis of fatigue characteristic of rail fastening clip for railways with passenger and freight traffic," Journal of $\mathrm{Me}$ chanical Engineering, vol. 54, 2018.

[5] X. Gao, A. Wang, L. Liu, Y. He, and L. Ju, "Analysis of failure mechanism of W1-type fastening clip in high-speed railway and structure study of damping composite," Engineering Failure Analysis, vol. 118, 2020.

[6] X. Gao, A. Wang, Y. He, and X. Gu, "Structural improvement of the $\omega$-type high-speed rail clip based on a study of its failure mechanism," Shock and Vibration, vol. 2019, Article ID 4127065, 14 pages, 2019.

[7] L. Ling, W. Li, H. Shang, X. Xiao, Z. Wen, and X. Jin, "Experimental and numerical investigation of the effect of rail corrugation on the behaviour of rail fastenings," Vehicle System Dynamics, vol. 52, 2014.

[8] H. Xiao, J. B. Wang, and Y. R. Zhang, "The fractures of e-type fastening clips used in the subway: theory and experiment," Engineering Failure Analysis, vol. 81, 2017.

[9] Y. F. Yang, L. Ling, Y. F. Yang, and K. Y. Wang, "Wheel/rail dynamic responses due to the wheel flat of heavy-haul locomotives," Engineering Mechanics, vol. 37, 2020.

[10] D. E. Holder, M. V. Csenge, Y. Qian, M. S Dersch, J. R Edwards, and J. V. D Brandon, "Laboratory investigation of the Skl-style fastening system's lateral load performance under heavy haul freight railroad loads," Engineering Structures, vol. 139, 2017.

[11] T. Xin, X. Yang, H. Xiao, and Q. Zhang, "Fatigue analysis of spring clip based on vehicle-track coupled model and detailed fastener model," Journal of Central South University, vol. 47, 2016.

[12] H. X. Shang, Z. F. Wen, and L. Wu, "Finite element analysis of type iii rail fastening clip failure in metro lines," Engineering Mechanics, vol. 32, 2015.

[13] S. Mohammadzadeh, S. Ahadi, and H. Keshavarzian, "Assessment of fracture reliability analysis of crack growth in spring clip type Vossloh SKL14," Proceedings of the Institution of Mechanical Engineers - Part O: Journal of Risk and Reliability, vol. 228, no. 5, pp. 460-468, 2014.

[14] S. Mohammadzadeh, S. Ahadi, and M. Nouri, "Stress-based fatigue reliability analysis of the rail fastening spring clip 
under traffic loads," Latin American Journal of Solids and Structures, vol. 11, 2014.

[15] J. Xiao, H. Hu, Z. Yan et al., "The influence of wheel/rail vibration on the damage of rail fastening system of high-speed railway in China," Delft University of Technology, in Proceedings of the 11th International Conference on Contact Mechanics and Wear of Rail/wheel Systems, Delft, Netherlands, September 2018.

[16] X. Yang, "Fatigue life analysis on ballastless track structures in turnout zone under complex loads," Master Thesis, Beijing Jiaotong University, Beijing China, 2017.

[17] A. Hasap, P. Paitekul, N. Noraphaiphipaksa, and C. Kanchanomai, "Influence of toe load on the fatigue resistance of elastic rail clips," Proceedings of the Institution of Mechanical Engineers - Part F: Journal of Rail and Rapid Transit, vol. 232, 2018.

[18] J. Wu, S. Wang, and Z. Wu, "An experimental research on toe load of fastening and fatigue life of WJ-7 type fastener"," "Journal of Kunming University of Science and Technology, vol. 03, pp. 120-125, 2019.

[19] H. Liu, "Failure analysis of railway clip fastener system," Master Thesis, Hebei University of Technology, Tianjin, China, 2017.

[20] T. Liu, "Study on fatigue and fracture mechanism of nonshoulder fastening spring clip in unballasted track of highspeed railway," Master Thesis, Beijing Jiaotong University, Beijing China, 2018.

[21] Z. Wang, "The failure analysis of two kinds of rail-fastener springs and finite element analysis," Master Thesis, Southwest Jiaotong University, Sichuan China, 2013.

[22] R. Manouchehrynia and S. Abdullah, "Fatigue reliability assessment of an automobile coil spring under random strain loads using probabilistic technique," Metals, vol. 10, no. 1, 2019.

[23] L. Abdullah, "Fatigue life-based reliability assessment of a heavy vehicle leaf spring," International Journal of Structural Integrity ahead-of-print, vol. 10, 2019.

[24] P. Zhang, Q. Zhu, G. Chen, H. Qin, and C. Wang, "Effect of heat treatment process on microstructure and fatigue behaviour of a nickel-base superalloy," Materials, vol. 8, 2015.

[25] W. Wang, S. Duan, H. Zhu, and B. Deck, "Research on improving the durability of bridge pavement using a highmodulus asphalt mixture," Materials, vol. 14, 2021.

[26] Y. Zhao and C. Ding, "Effect of heat treatment on microstructure and properties of $24 \mathrm{CrNiMo}$ alloy steel formed by selective laser melting (SLM)," Materials, vol. 14, 2021.

[27] X. Jiang, Y. Liu, J. Tang et al., "Nonlinear mechanical behaviour of $\omega$-type rail fastening spring clip," Materials for Mechanical Engineering, vol. 45, 2021.

[28] X. Jiang, Y. Liu, Q. Li, W. Zhao, and H. Liu, "Analysis of resonance response characteristics of the $\omega$-clip in fastener systems of high speed railways," Railway Standard Design, vol. 65, 2021.

[29] Y. Liu, Z. Wei, Q. Li et al., "An experimental study on the modal characteristics identification for the clip by using digital image correlation technology," Journal of Experimental Mechanics, vol. 24, 2021.

[30] Y. Liu, X. Jiang, Q. Li, W. Zhao, and H. Liu, "Fatigue life evaluation and prediction of the $\omega$-type clip in fastening systems," Journal of Tongji University (Natural Science), vol. 49, 2021.

[31] X. Shen, S. P. Zhu, Y. Z. Hao, and D. Liao, "A new critical plane-energy model for multiaxial fatigue life prediction of turbine disc alloys," Engineering Failure Analysis, vol. 93, pp. 55-63, 2018.
[32] S. Xu, S. P. Zhu, Y. Z. Hao, and D. Liao, "Critical plane-based multiaxial fatigue life prediction of turbine disk alloys by refining normal stress sensitivity," The Journal of Strain Analysis for Engineering Design, vol. 53, 2018.

[33] Z. Y. Yu, S. P. Zhu, L. Qiang, and L. Yunhan, “A new energycritical plane damage parameter for multiaxial fatigue life prediction of turbine blades," Materials, vol. 10, 2017.

[34] Z. Yu, S. Zhu, and Q. Liu, "Multiaxial fatigue damage parameter and life prediction without any additional material constants," Materials, vol. 10, no. 8, 2017.

[35] J. Liu, Z. Zhang, and B. Li, "Multiaxial fatigue life prediction of gh4169 alloy based on the critical plane method," Metals Open Access Metallurgy Journal, vol. 9, 2019.

[36] Z. R. Wu, X. Li, L. Fang, and Y. D Song, "Multiaxial fatigue life prediction based on nonlinear continuum damage mechanics and critical plane method," Journal of Materials Engineering and Performance, vol. 2, 2018.

[37] D. F. Socie and G. Marquis, "Multiaxial fatigue," Warrendale Pa Society of Automotive Engineers, vol. 24, pp. 195-201, 1999.

[38] D. Socie, Critical Plane Approaches for Multiaxial Fatigue Damage Assessment, ASTM International, PA, USA, 1993.

[39] Y. Wang and L. Susmel, "The Modified Manson-Coffin Curve Method to estimate fatigue lifetime under complex constant and variable amplitude multiaxial fatigue loading," International Journal of Fatigue, vol. 83, pp. 135-149, 2016.

[40] M. W. Brown and K. J. Miller, "A theory for fatigue failure under multiaxial stress-strain conditions," Proceedings - Institution of Mechanical Engineers, vol. 187, 1973.

[41] C. H. Wang and M. W. Brown, "A path-independent parameter for fatigue under proportional and non-proportional loading," Fatigue and Fracture of Engineering Materials and Structures, vol. 16, no. 12, pp. 1285-1297, 1993.

[42] C. H. Wang and M. W. Brown, Multiaxial Random Load Fatigue: Life Prediction Techniques and Experiments, Mechanical Engineering Publications, London, UK, 1996.

[43] S. P. Zhu, S. Foletti, and S. Beretta, "Probabilistic framework for multiaxial LCF assessment under material variability," International Journal of Fatigue, 2017.

[44] A. Fatemi and D. F. Socie, "A critical plane approach to multiaxial fatigue damage including out-of-phase loading," Fatigue and Fracture of Engineering Materials and Structures, vol. 11, no. 3, pp. 149-165, 1988.

[45] A. Ince and G. Glinka, "A generalized fatigue damage parameter for multiaxial fatigue life prediction under proportional and non-proportional loadings," International Journal of Fatigue, vol. 62, pp. 34-41, 2014.

[46] Z. Cui, Y. Kang, G. Zhu, and B. S Li, "Effect of process parameters on microstructure and properties of $1500 \mathrm{MPa}$ grade hot formed steel without boron but containing niobium," Proceedings of the Materials Science Forum, vol. 944, 2018.

[47] Z. Zhang and B. Andrawes, "Parametric study on the distribution of longitudinal load in railway track under dynamic wheel loading using finite element analysis," International Journal of Civil Engineering, vol. 2, 2015.

[48] J. Sadeghi, M. Fesharaki, and A. Khajehdezfuly, "Influences of train speed and axle loads on life cycle of rail fastening clips," Transactions of the Canadian Society for Mechanical Engineering, vol. 39, 2015.

[49] S. Zhu, Z. Yu, and J. Correia, "Evaluation and comparison of critical plane criteria for multiaxial fatigue analysis of ductile and brittle materials," International Journal of Fatigue, vol. 112, pp. 279-288, 2018.

[50] D. Liao, S. Zhu, and G. Qian, "Multiaxial fatigue analysis of notched components using combined critical plane and 
critical distance approach," International Journal of Mechanical Sciences, vol. 160, pp. 38-50, 2019.

[51] Z. Li, R. Q. Guo, and W. Shuai, "Effects of elastic strip deflection and fastening looseness on toe load of elastic strip," Railway Standard Design, vol. 60, no. 2, 2016.

[52] S. Timoshenko and J. N. Goodier, "Theory of elasticity," vol. 49, Engineering Societies Monographs, New York, NY, USA, 2nd edition, 1951.

[53] S. S. Manson, "Fatigue: a complex subject-some simple approximations," Experimental Mechanics, vol. 5, pp. 193226, 1965.

[54] C. Boller and T. Seeger, "Materials data for cyclic loading," Part A: Unalloyed Steel, vol. 42, North-olland, Amsterdam, The Netherlands, 1987.

[55] G. Zhang and W. Zhu, "Parameter sensitivity analysis and optimizing for test programs," Rock and Soil Mechanics, vol. 01, pp. 51-58, 1993.

[56] Y. Cheng, Analysis on the Strength and Fatigue Life of the W6Mo5Cr4V2 Steel Drive Shaft, Wuhan University of Technology, Wuhan, China, 2010.

[57] Y. Q. Cai, Y. Wang, Z. Cao, and C. Xu, "Study of ground vibration from trains caused by track irregularities," Yantu Lixue/Rock and Soil Mechanics, vol. 33, pp. 327-335, 2012.

[58] Q. Xu, O. Xi, A. Francis, P. Lou, and Z. C Xiao, "Effects of track irregularities on environmental vibration caused by underground railway," European Journal of Mechanics - A: Solids, vol. 59, 2016.

[59] J. Smutny, L. Pazdera, V. Nohál, and D. Vukusicova, "The effects of rail corrugations on noise and vibration," Akustika, vol. 28, pp. 79-89, 2017.

[60] X. Jia, G. Li, X. Liu, and P. Chen, "Research on the relationship between the rail corrugation and the vibration response of the wheel-rail system," MATEC Web of Conferences, vol. 308, Article ID 02002, 2020.

[61] H. Tanaka and M. Miwa, "Modeling the development of rail corrugation to schedule a more economical rail grinding," Proceedings of the Institution of Mechanical Engineers - Part F: Journal of Rail and Rapid Transit, vol. 234, 2019.

[62] "Sorting Out and Analysis of the Causes of Large-Scale Deceleration of Shenzhen Metro Line 11," https://www.bilibili. $\mathrm{com} / \mathrm{read} / \mathrm{cv6047878/.}$

[63] A. Carpinteri, "Size-scale transition from ductile to brittle failure," Fracture and Complexity. Solid Mechanics and Its Applications, Springer, vol. 237Dordrecht, Netherland, , 2021. 